\title{
Clinical Psychology for Dentist
}

\author{
Mohammad Qasem Abdullah* \\ Department of Counseling Psychology, University of Aleppo, Syria
}

Submission: November 13, 2017; Published: December 01, 2017

*Corresponding author: Mohammad Qasem Abdullah, Department of Counseling Psychology, University of Aleppo, Syria; Email: mk.abdalah@yahoo.com

\section{Introduction}

It has been increasingly recognized that the behavioral sciences have an important role in dental education, practice and research. Furthermore, the need for psychological interventions in dentistry is now supported by recent guidelines, as is the importance of providing the necessary psychological guidance and expertise in terms of treatment planning and clinical decision-making [1,2]. Psychology can be applied to all dental specialties ranging from the general practitioner to the experts in their respective fields and the dental surgeon itself, both as regards their professional tensions, the routine of his work, his personality and his behavior towards patients. The success in attendance, most of the time, does not concern the technical professional, although it is essential, however, «the patient is not only the technical expertise that does leave or stay in treatment.» The Psychology Applied to Dentistry can and should interact in the following areas: Orthodontics and Pediatric Dentistry: work and understand the poor habits (thumb sucking, nail biting, fears, phobias, mental disorders in childhood etc.).

Periodontics: surgery, periodontal diseases, relationship with stress and its differentiation with distress and frustration. Rehabilitation carrier cleft palate patient, as the patient will undergo numerous surgeries you have to work the pre and postsurgical ways of dealing with family. Special patients: congenital malformations, behavioral changes, physical changes acquired. For patients who are carriers of a major injury with different consequences is necessary to evaluate the residual potential in order to establish an individualized specific treatment plan in order to act, that is, each patient will require the dentist an adapted form of care to their history as well as its collaboration capabilities, intellection and availability to dental procedures.

Clinical psychology in dentistry should aim to:

a) Reduce distress associated with dental treatment.

b) Promote the uptake of necessary dental care.

c) Promote oral health. d) Assess the need for cosmetic dental care.

In dental practice, it is experienced that most of the children do not cooperate during dental procedures. Sometimes it becomes very difficult to manage a child in a dental clinic. These difficulties of management are not only related to the technical procedures of treatment, but also with the different emotional upsets of the child. The most common emotional upsets exhibited during dental treatment are anxiety and fear, which may originate from a previous traumatic experience in the dental office or during hospitalization for other purpose. Fear of dentistry and associated psychological difficulties, is a widespread problem prevalent in both children and adults. Patients who are highly anxious about receiving dental treatment may delay or cancel appointments, have difficulty in tolerating treatment whilst in the dental chair and setting, and may not access care at all. As a result, dental fear is reported as being the greatest difficulty faced by dentists in terms of managing their patients $[3,4]$. The aim of continuous dental care is for dentists to be able to make contact with patients in an easy, accessible and acceptable manner. For patients who may be described as 'regular attendees' dentists have been able to form and maintain a 'treatment' relationship. This enables patients to accept the care, which has been negotiated and offered.

With my background in clinical psychology and mental health and teaching the course of clinical psychology for dentists» over than nine academic years, I thought that we need to write about dental fears and phobias, pain and the relations of dentist-patient. The course we have been published for undergraduate students in the Dentistry College at University of Aleppo, entitled» Clinical psychology for dentists», University Press, 2015. This book provides information pertinent to the bio psychosocial aspects of dentistry. It discusses the needs of patients who require particular forms of care, thereby helping the general dental practitioner, scholars undergraduate, and to deal with nervous patients and enhance coping skills. Organized into ten chapters (335 pages), this edition begins with an 
overview of theoretical background and some of the problems that dentists encounter in managing patients. This text then explains the importance of preventive care in oral health, which includes both educational and motivational approaches. Other chapters provide suggestions for designing a preventive program that can be adapted for the use of individual patients. This book discusses as well the various types of pain, which is important for the understanding of psychological approaches to pain relief. The final chapter deals with the dentist's attitudes, behavior, and personality that are important for the understanding of dental care such as relation of dentist-patient, adherence, anxiety and mental disorders [4].

The contents of this book have been included the following Chapters:

\section{Part One: Theoretical background.}

a) Psychology: Its definition, significance, and aims.

b) Psychology and mental health: normality abnormality and its criteria,

c) Personality: Healthy personality.

d) Psychodynamic foundation of abnormal behavior and psychopathology (stress, frustration, defense mechanisms).

\section{Part Two: Clinical implications and dentistry.}

a) The psychology of patient in dentistry clinic: child, Adolescent and adult.

b) Psychology of compliance and adherence.

c) Psychology of the relationship between patient and doctor, (dentist-patient relation) compatibility, coping skills. d) Pain: its type, neurological foundation, its psychologicalneurological mechanism and theories, Pain management.
e) Mental disorders (DSM-V) (speech disorders, hyperactivity...)
f) Anxiety, Phobia and dentistry: Dentist phobia.

\section{Glossary}

This book is a practical guide to developing the necessary skills to conduct effective patient interviews (according to the developmental period), coping skills, and communication for dealing and manage the patient's dental fears and anxieties, and for dealing with patients who need counseling and clinical helping. This unique book identifies the everyday concerns of dentists, dental students, and offering proven strategies for patient management and for building-and maintaining-a successful dentist-patient relationship. It is included the topics of scientific and academic plan for undergraduate students in the Dentistry College at the University of Aleppo [5,6].

\section{References}

1. (1990) General Dental Council Guidance on the teaching of the behavioral sciences.

2. (1996) British Psychological Society Clinical Psychology in Dentistry.

3. Enneking D, Milgrom P, Weinstein P, Getz T (1992) Treatment outcomes for specific subtypes of dental fear: Preliminary clinical findings. Special Care in Dentistry 12(5): 214-218.

4. Larijani H, Guggisberg M (2015) Improving clinical practice: What dentists need to know about the association between dental fear and history of sexual violence victimization? International Journal of Dentistry 12.

5. Division of Clinical Psychology.

6. General Dental Council. London, UK.

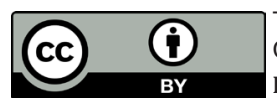

This work is licensed under Creative Commons Attribution 4.0 License DOI: 10.19080/PBSIJ.2017.07.555723

\section{Your next submission with Juniper Publishers will reach you the below assets}

- Quality Editorial service

- Swift Peer Review

- Reprints availability

- E-prints Service

- Manuscript Podcast for convenient understanding

- Global attainment for your research

- Manuscript accessibility in different formats

( Pdf, E-pub, Full Text, Audio)

- Unceasing customer service

Track the below URL for one-step submission https://juniperpublishers.com/online-submission.php 